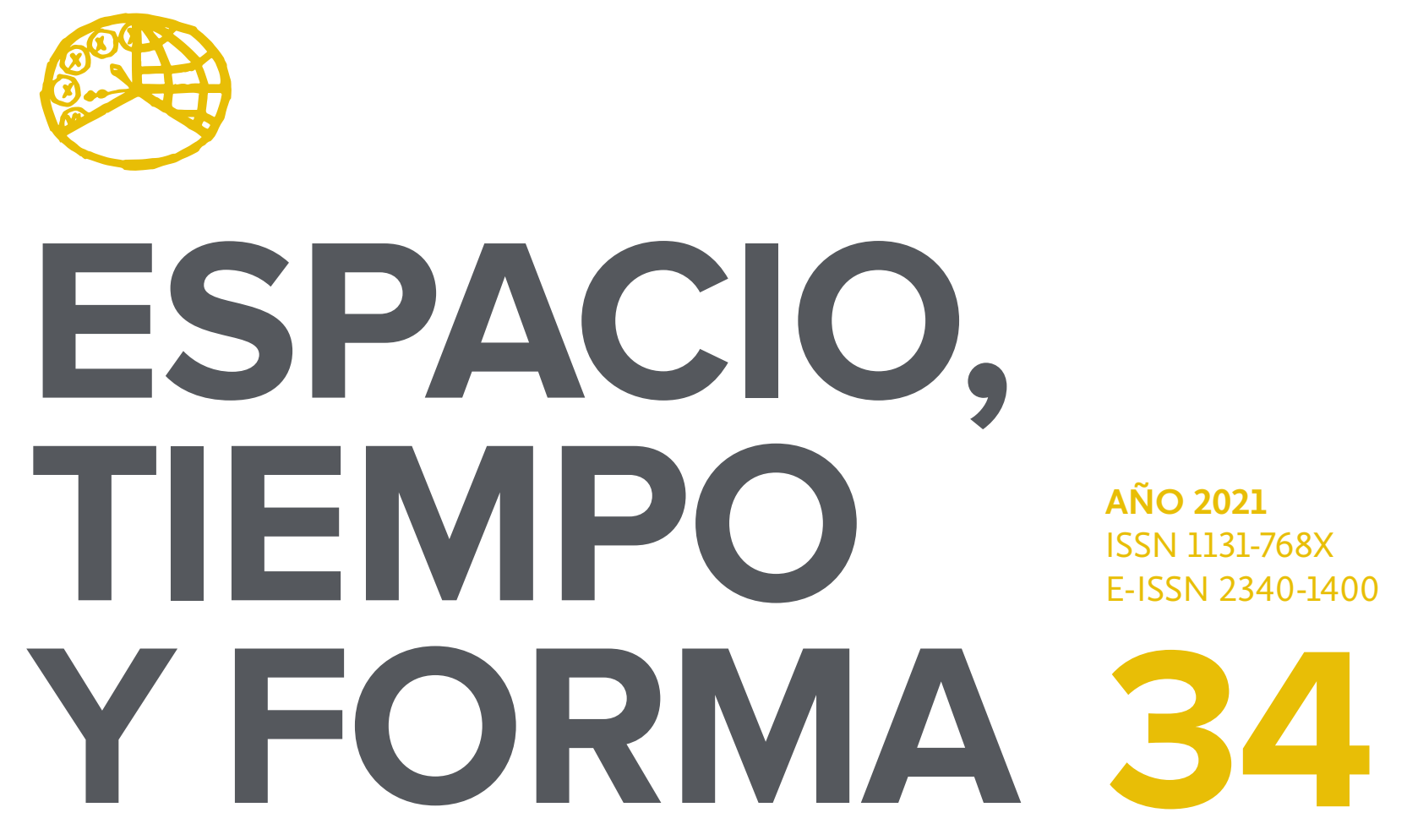

SERIE IV HISTORIA MODERNA

REVISTA DE LA FACULTAD DE GEOGRAFÍA E HISTORIA

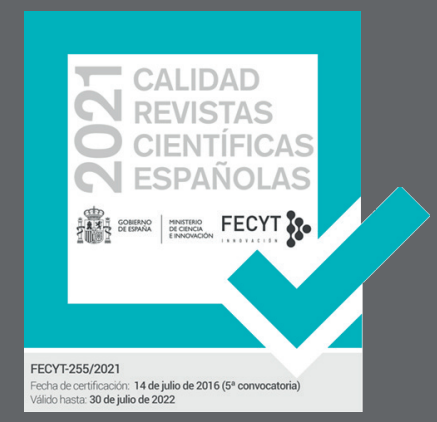




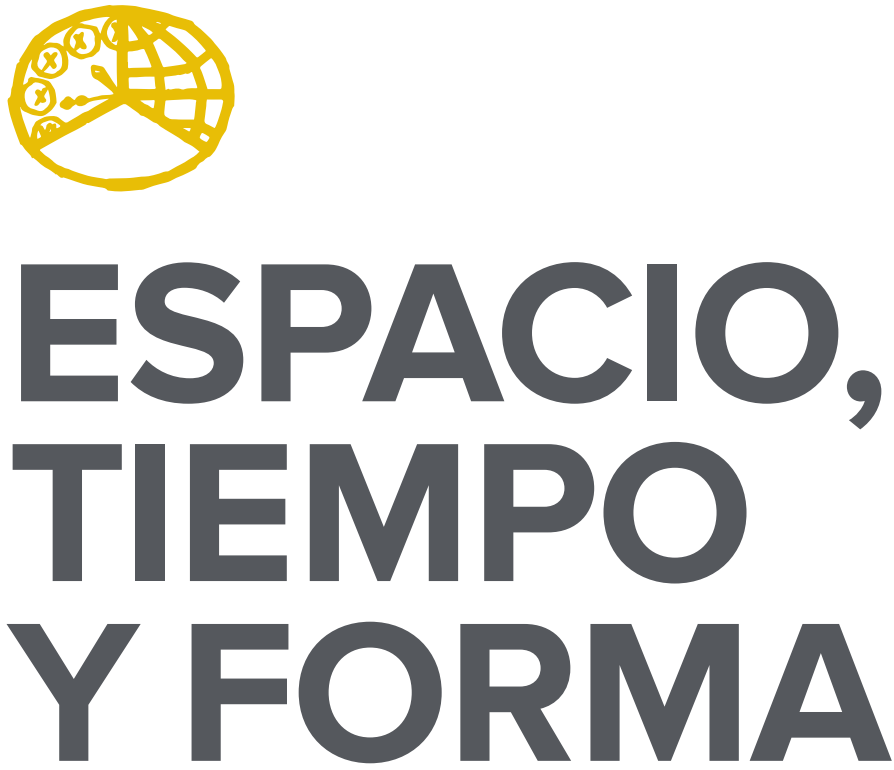

AÑO 2021

ISSN 1131-768X

E-ISSN 2340-1400

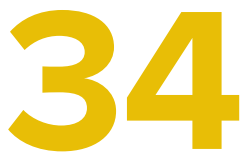

SERIE IV HISTORIA MODERNA

REVISTA DE LA FACULTAD DE GEOGRAFÍA E HISTORIA

DOI: https://doi.org/10.5944/etfiv.34.2021

\section{UกED}

UNIVERSIDAD NACIONAL DE EDUCACIÓN A DISTANCIA 
La revista Espacio, Tiempo y Forma (siglas recomendadas: ETF), de la Facultad de Geografía e Historia de la UNED, que inició su publicación el año 1988, está organizada de la siguiente forma:

$$
\begin{aligned}
& \text { SERIE I - Prehistoria y Arqueología } \\
& \text { SERIE II - Historia Antigua } \\
& \text { SERIE III - Historia Medieval } \\
& \text { SERIE IV - Historia Moderna } \\
& \text { SERIE V - Historia Contemporánea } \\
& \text { SERIE VI - Geografía } \\
& \text { SERIE VII - Historia del Arte }
\end{aligned}
$$

Excepcionalmente, algunos volúmenes del año 1988 atienden a la siguiente numeración:

$$
\begin{aligned}
& \mathrm{N} .^{\circ} 1 \text { - Historia Contemporánea } \\
& \mathrm{N}^{\circ} 2 \text { - Historia del Arte } \\
& \mathrm{N} .^{\circ} 3 \text { - Geografía } \\
& \mathrm{N} .^{\circ} 4 \text { - Historia Moderna }
\end{aligned}
$$

ETF no se solidariza necesariamente con las opiniones expresadas por los autores.

\author{
UNIVERSIDAD NACIONAL DE EDUCACIÓN A DISTANCIA \\ Madrid, 2021 \\ SERIE IV · HISTORIA MODERNA N. ${ }^{\circ} 34,2021$ \\ ISSN $1131-768 X \cdot$ E-ISSN 2340-1400 \\ DEPÓSITO LEGAL \\ M-21.037-1988 \\ URL \\ ETF IV · HISTORIA MODERNA · http://revistas.uned.es/index.php/ETFIV \\ DISEÑO Y COMPOSICIÓN \\ Carmen Chincoa Gallardo · http://www.laurisilva.net/cch \\ Impreso en España · Printed in Spain
}

(c) (7) (8) Esta obra está bajo una licencia Creative Commons Reconocimiento-NoComercial 4.0 Internacional. 


\section{MISCELÁNEA • MISCELLANY}





\title{
VICISITUDES DE LAS COMPAÑIAS DE RESCATE DE LAS NAVES HUNDIDAS EN LA BATALLA DE RANDE, 1719-1733
}

\section{VICISSITUDES OF THE RESCUE COMPANIES OF THE SUNKEN SHIPS IN THE BATTLE OF RANDE, 1719-1733}

\author{
Manuel-Reyes García Hurtado \\ Recibido: 03/04/2021 - Aceptado: 06/07/2021 \\ DOI: https://doi.org/10.5944/etfiv.34.2021.30590
}

\section{Resumen}

Tras el hundimiento de la flota procedente de Indias refugiada en la ría de Vigo en octubre de $\mathrm{I} 7 \mathrm{O} 2$ se iniciaron una serie de actividades de exploración submarinas para recuperar los restos de las naves. La idea de que gran parte del rico cargamento que portaban en sus bodegas se encontraba depositado en el fondo de la ría y, muy especialmente, la constancia de la presencia de elementos que a su valor material añadían su utilidad práctica (cañones y anclas), actuaron como catalizadores para la constitución de compañías extranjeras cuya única finalidad fue la recuperación de efectos de los pecios. Analizamos las trabas a las que tuvieron que hacer frente dos de estas sociedades que llegaron a Galicia y el papel jugado por el cuerpo consular francés.

Palabras clave

Batalla de Rande; buzos; rescate; cañones; consulado

\begin{abstract}
After the sinking of the fleet from the Indies sheltering in the Vigo estuary in October 1702, a series of underwater exploration activities began to recover the remains of the ships. The idea that a large part of the rich cargo that they carried in their warehouses was deposited at the bottom of the estuary and, very especially, the evidence of the presence of elements that added to their material value their practical utility (cannons and anchors), acted as catalysts for the constitution of foreign companies whose sole purpose was to recover the effects of wrecks. We analyze the obstacles faced by two of these companies that arrived in Galicia and the role played by the French consular corps.
\end{abstract}

\footnotetext{
1. Universidad de La Coruña; reyes@udc.es

Trabajo realizado en el marco del Proyecto I+D de Generación de Conocimiento «Dinámicas y conflictividad en el litoral del Noroeste peninsular en la Edad Moderna» (ref. PGC2018-093841-B-C33), del Ministerio de Ciencia, Innovación y Universidades, con una cofinanciación del 80\% FEDER.
} 


\section{Keywords}

Battle of Rande; divers; rescue; cannon; consulate 
EN LA BATALLA DE RANDE O DE VIGO (23 de octubre de I702) se enfrentan una escuadra anglo-holandesa con la flota que regresaba de Indias protegida por naves francesas ${ }^{2}$, que modificó su destino habitual en Cádiz (que había estado sitiada desde el 23 de agosto al 29 de octubre por la misma flota enemiga) buscando un destino alejado de la zona de conflicto, que finalmente le resultó funesto ${ }^{3}$. Este hecho bélico ha sido objeto de numerosos estudios, pero con la singularidad de que se ha prestado mucha mayor atención que a la batalla al cargamento procedente de América. No en vano, fue la captura del botín de los i4 galeones comerciales lo que motivó el enfrentamiento. Rande y $\mathrm{I702}$ se convirtieron en un mito para los cazatesoros $^{4}$, a pesar de que las numerosas expediciones que se han llevado a cabo en las aguas de la ría de Vigo desde el día siguiente al hundimiento de la flota de Indias hasta la actualidad han tenido como resultado que apenas se ha logrado recuperar del fondo algunas monedas o unas pequeñas bandejas de plata, que además no eran de una embarcación española, sino inglesa ${ }^{5}$. Por otro lado, las expediciones de rescate que se organizaron por parte de Francia en los primeros momentos no mencionaron otro elemento de interés que los cañones:

Desde que se tuvo conocimiento en Francia del triste acontecimiento, su Majestad escribió al señor [Ambroise] Daubenton, encargado de los asuntos de nuestra Marina en la Corte de Madrid, que se pusiera en correspondencia con el señor [Louis] Bru, vicecónsul en Vigo, para... la recuperación de los cañones y otros efectos de estos navíos.... No parece que esta pesca haya tenido mucho éxito, al menos es lo que hay que creer por los pocos cañones rescatados y de los cuales varios a menudo comprados por el rey de España ${ }^{6}$.

En conexión con las tareas de recuperación de la artillería y de las anclas se difundió la idea de que en el fondo de la ría se había depositado también el tesoro que llevaban en sus bodegas los galeones de Indias ${ }^{7}$ y se organizaron expediciones y trabajos de buceo desde 1702 y durante los siglos posteriores para recuperar los restos de la flota, sin el éxito anhelado ${ }^{8}$, porque el numerario fue desembarcado previamente al ataque ${ }^{9}$, de lo que se encargó el ingeniero francés Bernard Renau

2. Calvo Poyato, (1992). Abilleira Crespo, (2015).

3. Por otro lado, Vigo era un enclave en el que la presencia naval enemiga no era en absoluto inusual durante la Edad Moderna. Patiño Gómez, (2015), (2016) y (2018).

4. Las monografías tienen dos características principales, habitualmente su lugar de edición en España es Vigo y en su inmensa mayoría son firmes defensoras de la veracidad de la existencia de un tesoro: ROdRÍGUEZ ELÍAS, 1935 (1994); IberTI, 1942; POTTER, 1958 (2002); StÉnUIT, 1958 (1969 y 1992; en gallego, 1989); VÁzQUez GIL, 1985; JUEGA Puig, 2001; VV.AA., 2002; Lee, 2002; Abilleira Crespo, 2005; Bartolomé Benito, 2013; Patiño Gómez, 2014.

5. Véase VÁzQUez GIL, 1985: 14. La relación completa de todas las campañas de búsqueda en ABILLEIRA CRESPO, 2005: 160-163. La cifra oscila entre 49 y 70, dependiendo del autor; en cualquier caso, resulta evidente el interés que suscita el fondo de la ría viguesa. Los protagonistas, incluso los que emplearon los medios técnicos más avanzados en la actualidad, reconocen su fracaso: «No, no encontramos el oro y la plata que veníamos a rescatar». POTTER, 1958: 8.

6. Archives Nationales de París (en adelante, AN), MAR/B/4/22, (1702).

7. Véase García HuRtado, 2021 a.

8. Es fundamental en todo lo relativo al botín de los aliados, a las actividades de buceo que se realizan en 1702 y 1703 y a la inexistencia de metales preciosos en los pecios JUEGA PUIG, 2001: 131-151. Realiza un análisis detallado, fundamentado y cuantitativo. Sobre este último elemento es clave KAMEN, (1966): 165-173.

9. La importancia del tesoro todavía subsiste. En el Centro de Interpretación de la Batalla de Rande dos de los cinco módulos se dedican a «El tesoro» y «La búsqueda del tesoro». CONSTELA DOCE, (2014): 344. 
d'Éliçagaray ${ }^{10}$. La bibliografía que se ha ocupado del estudio de las iniciativas que se llevaron a cabo para extraer del fondo de la ría de Vigo los restos de las naves hundidas tras la batalla en las primeras décadas del siglo XVIII se fundamenta exclusivamente en documentos de la serie Marine de los Archives Nationales de París ${ }^{\text {II }}$. Merced a estos trabajos pioneros, poseemos referencias, conocemos los nombres de los protagonistas y una serie de datos incompletos, que en ocasiones son erróneos ${ }^{12}$. Lamentablemente, tanto los archivos franceses como españoles conservan muy escasa documentación sobre los buzos y sus actividades en la Edad Moderna. Más aún, en el caso de Francia, la investigación que hemos llevado a cabo en sus archivos solo nos ha permitido localizar un legajo sobre esta materia en el siglo XVIII en los Archives Nationales, pero que en la actualidad está desaparecido ${ }^{13}$. Sí que contamos con información sobre inventos que se ofrecen a ambas coronas ${ }^{14}$, de alguno de los cuales tenemos constancia que se llegó a poner en práctica.

Por tanto, ante el déficit que muestran las fuentes marítimas, en las siguientes páginas emplearemos la documentación del Centre des Archives Diplomatiques de Nantes para indagar en los problemas a los que tuvieron que hacer frente las dos principales compañías constituidas en el primer tercio del siglo XVIII con el objeto expreso de llevar a cabo trabajos de exploración y extracción submarina en la ría de Vigo. Ambas tuvieron que dotarse de un importante capital para movilizar naves, máquinas y hombres (singularmente unos especialistas que durante esta centuria recibirán cada vez mayor atención: los buzos ${ }^{15}$ ). Sin embargo, su capacidad financiera, su dominio técnico y la audacia de sus integrantes estaban diseñados para enfrentarse con el medio marino, no con inconvenientes que venían derivados de su procedencia extranjera y de la circunstancia de que algunas autoridades locales vieran en ellas la oportunidad de exigirles diversos derechos. Es precisamente debido a las dificultades y enfrentamientos surgidos entre los directores de las compañías y algunos ministros de rentas españoles por lo que podemos reconstruir todos los acontecimientos que vivieron en Galicia y conocer cuál fue el resultado de estas iniciativas empresariales. La documentación consular francesa aporta información fundamental, pues estas compañías contaron con el respaldo oficial de Francia. Unas veces porque habían firmado un acuerdo en París para la recuperación de efectos de las naves francesas hundidas en la ría. Y en otras ocasiones tanto por la existencia de ese acuerdo como porque sus responsables eran franceses. En ambos casos, cuando sus directores tengan

10. FontenelLe, 1721: 114. Sobre este personaje y su labor en Galicia, especialmente antes y después de la batalla, véase García HURTADO (en prensa).

11. BLOT, 2002: 227-230. PATIÑO GómeZ, 2014: 65-82.

12. Por ejemplo, se ubica a Alexandre Goubert en los años 40, cuando se encontraba en Vigo en 1728 (BLOT, 2002: 230) o a Boyer en 1747, cuando tenemos constancia de su concesión desde 1738 (PATIÑo GómEZ, 2014: 83).

13. AN, MAR/G/120. Plongeurs, scaphandres, appareils de plongée sous-marine, 1685-1798.

14. AN, MAR/G/111. Machines pour le relèvement des vaisseaux et de la pêche des objets tombés à la mer, 1641-1800.

15. Un estudio detallado de la tratadística, instrumentos y máquinas ideados a lo largo de la Edad Moderna para el buceo y su desarrollo en España en el siglo XVIII en GARCía HURTADO, (2021 b). A pesar de los años transcurridos, sobre el buceo en la historia de España la única monografía continúa siendo la de Rodríguez CuEvas e IVARS PERELLó, 1987, y sobre los inventos de equipos de buceo el referente es el artículo de GARCía TAPIA, (1995). 
problemas recurrirán inmediatamente al cuerpo consular, fundamentalmente al vicecónsul de Francia en Vigo, y si el tema lo requería al cónsul en La Coruña o hasta al propio embajador en la Corte, pero siempre por mediación de estos representantes en Galicia.

\section{LIEBERT WOLTERS VAN SIOHIELM (1719-1724)}

Coronel sueco, Wolters llega a Vigo en I7I9, provisto de una concesión para explorar el fondo de la ría durante tres años que había adquirido por 300 escudos, obteniendo un permiso equivalente por parte de Francia en $172 \mathrm{O}^{16}$. A finales de I720 Wolters, al tener conocimiento de la llegada de un nuevo embajador a Madrid (Maulévrier), le escribe para informarle de que Felipe V le había acordado un tratado para extraer los restos de los navíos hundidos en 1702 en la ría de Vigo (la patente de Felipe $V$ para bucear entre las naves españolas naufragadas es de marzo de I7ig; la licencia de Francia para extraer la artillería de sus embarcaciones es de un año y medio más tarde) ${ }^{17}$. Destacó el papel jugado por el vicecónsul en Vigo (JeanBaptiste Bru, sobrino del anterior vicecónsul), que incluso se desplazó a la Corte para lograr el beneplácito del rey, haciendo gala de «un celo extraordinario» ${ }^{18}$. Rogó al embajador que le honrara con su protección. Este activo papel de Bru se explicaba por el hecho de que la concesión francesa introdujo la novedad de que los trabajos de la compañía debían ser supervisados por él. Una vez de regreso en Galicia, Bru escribió al embajador agradeciéndole todas las atenciones que había tenido con él durante su estancia en Madrid. Recibió dos paquetes del Conseil de Marine, uno de los cuales le estaba dirigido a La Coruña y por su tamaño hizo que sus amigos pensaran que era la patente de cónsul (llegando a transmitirle sus felicitaciones), pero eran edictos reales de julio de I720 en favor de los inválidos, y el otro era la aprobación de las gestiones efectuadas para obtener el permiso de Felipe V para que Wolters pudiera rescatar («pescar») todos los efectos y restos de los navíos de Luis XIV en la ría de Vigo, siguiendo el tratado realizado entre Francia y Wolters. Deseaba saber qué resolución había tomado Felipe de Orleans (regente de Francia) sobre este tema, a fin de que tanto Wolters como él pudieran indemnizarse «de los importantes gastos que nos ha ocasionado esta empresa» ${ }^{19}$. La noticia de que debían aguardar órdenes del Conseil de Marine que le transmitió Bru a Wolters, a instancias de la embajada, le determinó a escribir a Maulévrier para hacerle presente que llevaba meses preparado en Vigo y que hasta ahora solo había tenido gastos, provocándole desazón que se acercara la primavera y no poder llevar a cabo el inicio de sus trabajos ${ }^{20}$.

16. BLOt, 2002: 229-230. PATiÑo GómeZ, 2014: 75-79.

17. AN, MAR/B/4/22, f. 368 .

18. Liebert Wolters van Siohielm a Jean-Baptiste Louis Andrault (marqués de Maulévrier). Rande, 19/XII/1720. Archives Diplomatiques Centre de Nantes (en adelante, ADCN). 396PO/A/18. Todas las referencias textuales han sido traducidas al castellano por el autor.

19. Bru a Maulévrier. Vigo, 10/IV/1721. ADCN, 396PO/A/18.

20. Wolters a Maulévrier. Rande, $11 / \mathrm{IV} / 1721 . \mathrm{ADCN}, 396 \mathrm{PO} / \mathrm{A} / 18$. 
Los problemas surgieron de inmediato, pues los primeros objetos en extraerse fueron anclas, y esta clase de elementos no tenían marcas, de modo que no se podían diferenciar las francesas de las españolas, tan solo por la zona de extracción. Esto determinó que el vicecónsul remitiera una memoria a Maulévrier donde le informaba que habiéndose desplazado el 28 de abril a Rande, donde estableció su residencia Wolters mientras realizaba las labores de recuperación de los restos de las naves españolas, observó siete anclas de ro a 30 quintales que podían ser útiles. $\mathrm{Al}$ parecerle que algunas podían ser de fábrica francesa le preguntó a Wolters de qué lugares las había extraído y este señaló que procedían de las cercanías de la cadena que había dispuesto Château-Renault para impedir la entrada de la flota anglo-holandesa, a medio cuarto de milla de donde trabajaba en la recuperación de los restos españoles. Dado que la cadena estuvo integrada exclusivamente por embarcaciones francesas le señaló a Wolters, oralmente y por escrito ${ }^{21}$, que no debía confundir estos restos con los de España y que llevaría a cabo acciones para recuperarlas ${ }^{22}$. En esto no hacía sino seguir las instrucciones recibidas de la embajada el 6 de marzo anterior. Algunas de las anclas tenían un valor de más de 200 pistolas $^{23}$, por lo que Maulévrier debía lograr que el rey aceptara la entrega a Bru de todas aquellas que las gentes del lugar determinasen tener una procedencia francesa por su emplazamiento en el fondo marino. Obviamente, esto exigía conocer la ubicación de las naves en el momento del combate y hundimiento ${ }^{24}$. Del mismo modo, informó al Conseil de Marine y solicitó al embajador que interviniera para que se llegara a un acuerdo entre las dos coronas, porque temía que si el intendente de Galicia tenía algún papel en esta cuestión le remitiría a Madrid para dificultarle su tarea. Para no importunarle con este asunto le sugería que si lo deseaba enviaría sus memorias a Jean-Baptiste Robin (consejero de finanzas al servicio del embajador ${ }^{25}$. El vicecónsul señaló a Wolters que, dado que lo que estaba extrayendo eran anclas procedentes de la cadena que mandó colocar Château-Renault, todas ellas sacadas de naves francesas, indicase el día y el lugar en que cada ancla fue recuperada y que informase de esto al veedor, para que llegado el momento pudiera reclamarlas. Este asunto lo consideraba de la mayor importancia y no debía retrasar su ejecución ${ }^{26}$. El Conseil de Marine ordenó a Bru que se ciñera a las indicaciones que le diera el embajador y él se comprometió a mantenerle informado de todo lo que se rescatara. Así, siguiendo instrucciones

21. Bru a Wolters. 29/IV/1721. ADCN, 396PO/A/18.

22. Si bien el 21 de agosto de 1721 se ordenó que se separasen las anclas que se extrajeran en la proximidad del emplazamiento de la cadena, aceptando que estuvo integrada exclusivamente por navíos franceses, el 12 de octubre el veedor comunicó que las noticias que había recabado indicaban que participaron barcos de España y de Francia, por lo que consultó qué se debía hacer con las anclas. Finalmente, el 4 de marzo de 1722, Andrés de Pes ordena a Rodrigo Caballero que las anclas extraídas en esa zona se entreguen a Francia, pues los informes certificaban que la estacada la configuraron los franceses. Francia podía disponer de las anclas sin que se le pudiera plantear ningún embarazo. José Gutiérrez de Cevallos a Bru. Rande, 26/III/1722. ADCN, 396PO/A/20.

23. No existe consenso sobre la equivalencia de una pistola, porque diferentes autores señalan distintos valores. Nos inclinamos por considerar que una pistola equivaldría a 180 reales de vellón. Agradecemos a Francisco Cebreiro Ares su asesoramiento en esta cuestión. Véase JAMBU, 2013.

24. Memoria de Bru a Maulévrier. Vigo, 8/V/1721. ADCN, 396PO/A/18.

25. Bru a Maulévrier. Vigo, 8/V/1721. ADCN, 396PO/A/18.

26. Bru a Wolters. Vigo, 29/IV/1721. ADCN, 396PO/A/18. 
de Maulévrier se desplazó hasta La Coruña para entregar al intendente un escrito de este relativo a la extracción de restos de las naves francesas en la ría de Vigo. El intendente le remitió a José de Arillaga, comisario ordenador residente en Pontevedra, para que ejecutase lo que determinara el secretario de Marina (Andrés de Pes) ${ }^{27}$. Tal y como había avanzado, el intendente intervino para dilatar las actuaciones.

El órgano rector de la Marina francesa hizo llegar a Bru una memoria instructiva sobre este tema, conminándole a seguir con atención los trabajos efectuados en la ría e informar de los mismos, al tiempo que aprobaba las medidas que había sugerido para que no se confundieran las anclas francesas con las que provinieran de las naves españolas ${ }^{28}$. Al no obtener respuesta de la embajada le dirigió nuevamente la carta que había enviado el 8 de mayo, así como la memoria, por si no las habían recibido, adjuntando la resolución del Conseil de Marine instando a que el embajador representase ante Felipe $V$ que las anclas extraídas eran francesas, máxime cuando el intendente le había encaminado a Madrid, temeroso de que se confundieran con los restos españoles.

Los trabajos sobre los barcos franceses se iniciaron el 6 de junio. Durante todo ese mes solo se localizaron maderas, hasta que el día 30 se extrajo un cañón de bronce de 36 libras con las armas del rey de Francia. Ya en julio, los días i2 y i4 se recuperaron otros dos cañones galos similares. Wolters y sus socios necesitaban comenzar a rentabilizar la inversión que habían realizado y con la que sufragaban los gastos de dos embarcaciones y los salarios de más de sesenta hombres, lo que le llevó a plantear su venta tanto a España como a Portugal. Para frenar esto el vicecónsul se comprometió con uno de los prestamistas de Wolters (al que él mismo había entregado i ooo piastras), pero el empresario le señaló que tenía una gran necesidad de numerario y que no era suficiente garantía, por lo que buscó comprador. Imploró al embajador que escribiera a Wolters para que no llevase a cabo la venta, pues no había logrado que este aguardase a que en Vigo se recibiera la resolución de Versalles a este respecto ${ }^{29}$. En la tarde del I8 de julio se recuperó un cuarto cañón ${ }^{30}$. El embajador medió entre el vicecónsul y el empresario sueco. Al segundo le felicitó porque su proyecto estuviera obteniendo sus primeros frutos, rogándole que conservara en un lugar distinto los cañones franceses para evitar confusiones, y le informó de que le había ordenado a Bru que actuase de concierto con él, de modo que no le planteara «ninguna mala dificultad» y que él tampoco la encontrase por parte de Wolters ${ }^{31}$. Al vicecónsul le dio a conocer su carta al sueco y que estaba a la espera de que París aprobase la compra. Le notificó las quejas que había recibido de Wolters sobre «algunas dificultades» que le planteaba Bru (el sueco no las detalló, pero evidentemente

27. Bru a Maulévrier. La Coruña, 18/V/1721. ADCN, 396PO/A/18.

28. Louis-Alexandre de Bourbon (conde de Toulouse, presidente del Conseil de Marine) a Bru. París, 14/VI/1721. ADCN, 396PO/A/18.

29. Bru a Maulévrier. Vigo, 18/VII/1721. ADCN, 396PO/A/18.

30. Bru a Maulévrier. Vigo, 24/VII/1721. ADCN, 396PO/A/18.

31. [Maulévrier] a Wolters. El Escorial, 1/VIII/1721. ADCN, 396PO/A/18. 
se refería a la insistencia del vicecónsul en que no vendiera a nadie los cañones, excepto a Francia), exhortándole a mantener una buena relación con él, a fin de que el Conseil de Marine pudiera obtener los mayores beneficios de los trabajos que se efectuaban en Vigo. Añadía que en la tarde del I de agosto iba a entregar un memorial a Felipe $V$ para que ordenase que los cañones franceses se separasen de los españoles, y esperaba obtener una orden que enviaría a Bru inmediatamente para que pudiera emplearla ante el intendente ${ }^{32}$.

Los meses transcurrieron y se siguieron recuperando cañones franceses (6 de 36 libras y 2 de 24). Si bien ahora el problema fueron las anclas que se extrajeron, pues, aunque el marqués de Grimaldo había ordenado que las pertenecientes a Francia debían entregarse al vicecónsul, el intendente, nuevamente hace acto de presencia interponiéndose, todavía no había tomado una decisión al respecto, por lo que Bru solicitó que desde la embajada se informase de esto a Grimaldo, ya que el regente había ordenado que se solventara esta cuestión, y que sirviera de regla para las dificultades que surgieran en el futuro ${ }^{33}$. De hecho, de las nueve anclas rescatadas hasta enero de $\mathrm{I} 722$, dos se rompieron, una la empleó Wolters en uno de los barcos que utilizaba en la ría y otra la vendió a un navío que desde Brasil se dirigía a Oporto, todo lo cual alertó a Bru del peligro de que las restantes tuvieran el mismo destino. Rogó al intendente que interviniera para que Wolters mantuviera reunidas en un lugar las anclas francesas y al Conseil de Marine que solicitase al sueco que se mostrara más favorable a los intereses franceses ${ }^{34}$. La capacidad de presión del vicecónsul era casi inexistente, pues el intendente actuó siempre como un adversario (las resoluciones de la Corte que le presentó Bru no sirvieron más que para que el intendente solicitara instrucciones a Madrid, lo que le permitía retrasar cualquier actuación) y el sueco se movió por intereses económicos.

Los acontecimientos dieron un giro inesperado. Wolters fue arrestado, todo indica que a instancias de una denuncia de Bru. Según el sueco, en agosto de I72I recibió la notificación de la embajada del deseo de Francia de adquirir los cañones de sus embarcaciones, pero poco después Bru le comunicó que el Conseil de Marine le había señalado que podía hacer uso de ellos, pues Versalles no los necesitaba. Las autoridades españolas le indicaron que España tenía preferencia en la adquisición de dichos cañones sobre cualquiera, si bien tras varios meses le expresaron que no les interesaban y que podía disponer de ellos, y tras cinco semanas recibió un permiso expreso para esto. Así pues, embarcó dos cañones y dejó otros dos y una parte de un tercero, para seguridad de sus acreedores hasta su regreso, colocando al frente de los trabajos submarinos a un familiar. Según Wolters, se ciñó escrupulosamente a lo que le permitían los acuerdos con ambas coronas. Sin embargo, al día siguiente todos sus bienes fueron embargados y uno después él fue detenido por una compañía de soldados. Señaló que le sorprendió

32. [Maulévrier] a Bru. El Escorial, 1/VIII/1721. ADCN, 396PO/A/18

33. Bru a Valcourt (secretario de la embajada de Francia en Madrid). Redondela, 31/XII/1721. ADCN, 396PO/A/20.

34. Bru a Maulévrier. Redondela, 22/I/1722. ADCN, 396PO/A/20. 
descubrir que tras estas medidas se encontraba Bru, a quien acusaba de «usar métodos indecentes y ruines»:

era uno de los principales actores en este asunto, porque habiéndose aliado con el inspector o veedor [José Gutiérrez de Cevallos] de su majestad católica y con cierto portugués, han intrigado y conspirado juntos, sobre pretextos frívolos, para arruinar el crédito de dicho empresario [Wolters]... todo por una pasión mal reglada de algunos particulares, que esperan sacar provecho con mi ruina35.

Wolters presentó su situación personal como un grave perjuicio para los intereses de Francia y España, pues si no recuperaba la libertad y sus bienes no podría ejecutar los acuerdos firmados (precisaba liquidez para reanudar los trabajos en primavera y pagar los salarios a los obreros y buzos) y ambas coronas no se beneficiarían de sus extracciones. Además del daño directo a su empresa, esto creía que difundiría una imagen negativa que desincentivaría que otros participasen en este negocio en el futuro. Al tiempo que informaba al embajador, notificó lo sucedido al cónsul en Galicia, Jean-Baptiste Dauvergne (junio de I72I-noviembre de I735), para que el Conseil de Marine conociera la tesitura en que se hallaba. Al cónsul le expuso de una manera mucho más directa que Bru actuó como su enemigo de manera abierta: «soy escandalosa y continuamente perseguido»; «Bru maquina siempre cábalas contra mí con el veedor». Lo cierto es que Wolters se mostró muy celoso de proteger sus instrumentos y máquinas tanto del vicecónsul como del veedor, llegando a prohibir al segundo que se aproximara al lugar en que se efectuaban los trabajos subacuáticos. Esto no impidió que Bru remitiera a Francia una descripción pormenorizada del equipo empleado por los buzos ${ }^{36}$. Wolters se consideraba un empleado al servicio del rey de Francia y, por tanto, bajo la protección real, de modo que le suplicó que dirigiera una representación al intendente general (Rodrigo Caballero) para que ordenase que se retiraran las guardias que le habían colocado, «por un movimiento de su propia pasión e instigado por mis enemigos, de los cuales el señor Bru es uno de los jefes con un portugués». Llegó a solicitar que se relevase a Bru de la función de supervisor de sus trabajos, pues «me es imposible comportarme con este hombre» ${ }^{37}$, que se le concediera la libertad y que se le otorgase la jurisdicción al capitán general, pues el intendente hacía caso omiso a todas sus instancias, "por fines particulares», «mandando que este, por ningún motivo, se introduzca en el conocimiento de esta dependencia $»^{3}$.

Cuando Dauvergne pidió al intendente que se levantase el arresto a Wolters le informó que su situación obedecía a que debía dinero a diversas personas. El cónsul averiguó que era cierto que existía una reclamación de deuda, pero esta

35. Wolters a [Maulévrier]. Rande, 12/II/1722. ADCN, 396PO/A/20.

36. Vigo, 12/VI/1721. AN, MAR/B/2/182, ff. 182-183.

37. Wolters a Dauvergne. Rande («lugar de mi arresto»), 12/II/1722. ADCN,396PO/A/20. Bru actuaba como agente al servicio de los intereses de Francia. El 1 de marzo el Conseil de Marine ordenó a Bru que enviase tres cañones a La Rochelle, en el primer navío que partiera de Vigo, a la atención de Rostan, comisario de Marina, así como la relación de todo lo extraído en 1721. Louis-Alexandre de Bourbon a Bru. París, 1/III/1722. ADCN, 396PO/A/20.

38. Memoria de Wolters a la Corona. Sin fecha (1722). ADCN, 396PO/A/20. 
solo era una excusa: «desde entonces he descubierto que el señor Bru, el comisario [veedor] español [Cevallos, su cometido era inspeccionar lo rescatado en el buceo] y un tal don Miguel Avilés [Miguel de Avilés Carneiro e Chaves], portugués, actuaban de concierto para obligar al señor Siohielm a abandonar para hacerse con esta empresa»39. Wolters había acordado con Avilés entregarle el 30\% de lo que rescatase cuando negoció con España los trabajos submarinos en Vigo, y este último estimaba que esto era extensible a los efectos de las embarcaciones francesas, si bien el trato con Francia se efectuó mucho tiempo después y en la convención con el portugués no se hacía mención alguna a sus restos. Dauvergne informó de todo al Conseil de Marine, incluyendo que Bru participaba en el negocio, pues le había prestado dinero a Wolters (a cambio de una hipoteca sobre un cañón), por lo que tenía un interés material directo, más allá de su labor como representante de Francia. Finalmente, solicitó que se intercediera ante Grimaldo para que Wolters fuera puesto en libertad. Por su parte, Bru reconoció abiertamente que era cierto cuanto descubrió el cónsul, así como su animadversión por Wolters («nuestro sueco hace todo lo posible por escaparse»), quien llevaba detenido en su domicilio desde el 29 de enero y vigilado por un oficial y varios soldados. Sus deudas eran cuantiosas y sus acreedores temían que no las satisficiera:

Debe más de 12000 piastras, de las cuales yo tengo la desgracia de que 1000 son a mí. Si usted conoce algún buen agente que quiera encargarse de hacerme pagar yo le daría 200. Porque hay efectos, pero este sueco habiéndose sabido ganar a los jueces, no es posible obtener un decreto contra él. Creo que estaré obligado a enviar una memoria sobre esto al marqués [de Maulévrier] ${ }^{40}$.

Sin embargo, la versión de Bru era distinta. Según este el arresto se debió a una solicitud del veedor, al descubrirse que Wolters planeaba marcharse con tres cañones de fundición de los más grandes de los cinco que le habían correspondido en el rescate de los navíos del rey de Francia, que había embarcado en un navío inglés, sin informar a nadie. Al propio vicecónsul le extrañaba la duración del arresto, máxime cuando el intendente había ordenado que no se le impidiera seguir su plan, siempre que dejara una fianza suficiente para cubrir lo que sus acreedores le demandaban, a cuyo fin se requisaron todos sus bienes y dejaba en Vigo las máquinas y aparatos, así como a un responsable para continuar los trabajos de rescate. Wolters estaba en conversaciones con uno de los interesados para que se obligara a todo lo que le exigía el intendente, excluyendo el salvamento de los navíos. Esto le hacía sospechar a Bru que Wolters se viera tentado a no regresar y quedarse con el producto de lo obtenido en su primer año, con la pérdida consecuente para la Corona, que por el acuerdo debía obtener la mitad de todo lo extraído el segundo año y dos tercios el tercero sin ningún gasto ${ }^{41}$.

39. Dauvergne a [Maulévrier]. 15/III/1722. ADCN, 396PO/A/20. Toda la correspondencia de Dauvergne está fechada en La Coruña.

40. Bru a Valcourt. Redondela, 26/III/1722. ADCN, 396PO/A/20.

41. Bru a Maulévrier. Vigo, 26/III/1722. ADCN, 396PO/A/2O. 
Felipe de Orleans ordenó a Bru que remitiera a Francia los tres cañones de fundición extraídos, pero había dos obstáculos para llevar esto a cabo. En primer lugar, los barcos franceses no tenían acceso al puerto de Vigo sin una autorización expresa del rey de España, que solo poseían los procedentes de Martinica, de la pesca de la ballena o de Terranova, pero de todos estos puede que en diez años solo uno hiciera escala allí y llevase como destino La Rochelle. Sin embargo, con Portugal el tráfico era mucho más habitual, de modo que propuso escribir a alguno de sus corresponsales allí y que le enviase una embarcación en su viaje de regreso, para lo que la embajada debía obtener que la Corona le permitiera entrar en Vigo. En segundo lugar, todos los bienes de Wolters estaban requisados, incluidos los cañones, lo que inducía a sospechar que sus acreedores no permitirían que se embarcara nada de su propiedad ${ }^{42}$. En enero de 1722 se cuantificó el resultado de los trabajos submarinos en 8 cañones, con un peso total de 49776 libras, correspondiendo a la Corona por el acuerdo de I de septiembre de I720 un tercio (I6 592 libras). Así pues, dado que los tres cañones pesaban i8 685 libras, el exceso de 2093 libras correspondía a Wolters y, por tanto, iba en detrimento de su patrimonio. Su salida de Vigo disminuía sus bienes y debilitaba la respuesta ante sus deudas, por lo que Maulévrier debía obtener de la Corona española que ninguna justicia se opusiera a la marcha de los cañones de España bajo ningún pretexto ${ }^{43}$.

Dauvergne se posicionó a favor de Wolters, que consideraba que era objeto de una injusticia. Remitió al embajador una petición a Felipe $V$ en nombre del sueco para que este asunto saliera de la esfera del intendente, por su «parcialidad manifiesta» por el portugués, y se remitiera al capitán general, marqués de Risbourq ${ }^{44}$. Por otro lado, el cónsul ya había informado ampliamente a Risbourq de este asunto. El transcurso del tiempo y el no tener respuesta del embajador le «mortifica mucho», pues sentía que todos sus desvelos por los intereses de Francia eran en vano, mientras «se hace perecer lentamente al pobre» Wolters ${ }^{45}$. En junio Valcourt le informó de que el embajador no había recibido el memorial, y el cónsul aprovechó para exponer la lamentable situación en que se encontraba Wolters:

este gentilhombre habría muerto de miseria, con cinco o seis hombres que le quedan, sin el socorro que les he dado y les doy actualmente. Hace alrededor de tres semanas que el intendente envió uno de sus criados para ejecutar la sentencia contra él en favor de un portugués, por la cual se ordenó requisar todos sus bienes y efectos en beneficio de dicho portugués, y eso en perjuicio de los fondos avanzados para el servicio del rey, a saber 900 piastras que proporcionó el señor Bru [él había señalado que eran 1 0oo, como vimos], anteriormente encargado de la inspección del rescate [había sido relevado, como deseaba Wolters], las cuales fueron hipotecadas sobre un cañón, el dinero que le he entregado desde entonces, los salarios de los criados y otras deudas anteriores a las del portugués. A pesar de eso continúa todavía detenido en su casa sin poder trabajar, lo que es de un

42. Bru a Maulévrier. Vigo, 16/IV/1722. ADCN, 396PO/A/20

43. Memoria de Bru a Maulévrier. Vigo, 16/IV/1722. ADCN, 396PO/A/20. En los sucesivos repartos de lo rescatado se compensó esta pérdida de Wolters.

44. Dauvergne [a Maulévrier]. 29/III/1722. ADCN, 396PO/A/20.

45. Dauvergne [a Valcourt]. 17/V/1722. ADCN, 396PO/A/21. 
gran perjuicio para él, que desaprovecha el mejor tiempo para la pesca. El señor Dupuy, que he enviado a Vigo como vicecónsul, me señala que las oposiciones que realizó a la incautación de los dos cañones pertenecientes a Wolters no han impedido que el criado del intendente los haya conducido a Vigo ${ }^{46}$.

En julio Dauvergne señaló que no podía seguir ayudando económicamente a Wolters, al que ya había prestado I30 pistolas. Había presentado un memorial al intendente para que se obligara al agente del portugués, que contaba con dos cañones de fundición, a que le suministrase alimentos al sueco y a sus hombres. La respuesta del intendente fue que correspondía al procurador de Wolters efectuar la petición. Una vez realizada esta, la respuesta fue ambigua. El cónsul consideró que solo se perseguía prolongar el proceso y provocar la muerte del sueco. Lamentaba ver transcurrir los mejores meses del año sin que se efectuasen trabajos en la ría, máxime cuando un buzo le indicó que si Wolters hubiera estado libre se podrían haber rescatado siete $\mathrm{u}$ ocho cañones de bronce. Para él era sorprendente que el intendente ni le facilitase los medios de subsistencia a Wolters ni le permitiera obtenerlos por sí mismo llevando a cabo la empresa para la que se encontraba allí. El estado de Wolters era lastimoso ${ }^{47}$. Este envió a Dauvergne un expreso donde solicitaba que se recurriera la sentencia que se había fallado. El cónsul no confiaba en que se fuera a remitir el conocimiento de este asunto al capitán general, ya que este y el intendente «no congenian», lo que garantizaría una solución favorable, pues Risbourq «está dispuesto a contentarme» ${ }^{4}$.

El embajador presentó un memorial en la Corte para que Wolters fuera liberado y pudiera retomar su tarea. Al mismo tiempo Dauvergne dirigió otro al intendente donde demandaba la libertad del sueco y la devolución de dos cañones que había requisado, pues pertenecían al rey de Francia. En su respuesta el intendente afirmó que la libertad de Wolters solo dependía de que el cónsul se responsabilizara de él y de todos los bienes embargados, avalando que no se fugaría y respondiendo en su caso con sus propios bienes ante los acreedores. Si Dauvergne aceptaba Wolters sería liberado y se le reintegrarían sus propiedades. El cónsul elaboró un segundo memorial, pero decidió ir a hablar con el intendente antes de enviárselo. Dauvergne no dominaba suficientemente el castellano y el intendente no conocía el francés, pero hablaba aceptablemente latín, de modo que redactó una breve recapitulación en latín. En el curso de su reunión descubrieron que el intendente era amigo del comerciante Jean Stalpaert, con quien tenía deudas Wolters, y el cónsul le indicó que no le daba pruebas de amistad si no permitía al sueco trabajar para poder satisfacer lo que le debía. El intendente afirmó que deseaba ser amigo del cónsul y que para demostrárselo iba a hacer todo lo posible por el sueco, al tiempo que le encargaba a Dupuy (vicecónsul de Vigo, que acompañó a Dauvergne) que buscara al procurador de Wolters para que le pudiera comunicar qué debía realizar para resolver este

46. Dauvergne [a Maulévrier]. 14/VI/1722. ADCN, 396PO/A/20.

47. Dauvergne [a Maulévrier]. 4/VII/1722. ADCN, 396PO/A/21.

48. Dauvergne a Valcourt. 12/VII/1722. ADCN, 396PO/A/21. 
asunto ${ }^{49}$. El intendente cumplió su palabra y liberó a Wolters, obligando al agente de Avilés a entregarle 50 pistolas para poder continuar los trabajos. Sin embargo, esto sirvió al cónsul para concluir que el intendente había actuado hasta entonces con malicia o con ignorancia (se inclinaba a pensar que habían intervenido ambas). No de otro modo se explicaba que no se hubieran atendido antes las peticiones del procurador de Wolters: «No comprendo la actuación de este intendente, que me ha confesado haberlo oído todo a medias, incluso me enseñó la oreja izquierda». Por otro lado, el daño ya estaba hecho, pues su arresto le había provocado quebranto económico, pérdida de trabajadores (se habían marchado) y le había impedido realizar extracciones en la mejor época del año. El origen del problema estaba en la asunción de la jurisdicción por el intendente (el cónsul solo la reconocía sobre los efectos procedentes de las naves españolas), cuando todas las causas relativas a los franceses y a sus bienes eran competencia del capitán general. Valcourt le había informado que el rey había remitido este asunto a Andrés de Pes, que era lo mismo que si se lo hubiera encomendado al intendente. El cónsul contraponía la justicia del capitán general con la del intendente, pues una era rápida y expeditiva, mientras que la otra solo perseguía multiplicar y dilatar los procedimientos y acabar con los recursos del demandante. Lo que solicitaba no era algo excepcional, sino el cumplimiento de los tratados entre Francia y España ${ }^{50}$.

A pesar de lo que Dauvergne había informado, unos días después señaló que no había novedades y que Wolters continuaba prisionero en su casa ${ }^{51}$. Finalmente, en un encuentro fortuito con el intendente el 9 de agosto, cuando él se dirigía a misa y el segundo regresaba de un viaje a Tuy, Vigo y Santiago, le informó que había visitado al coronel sueco y que lo había resuelto todo, «de manera que él debía estar contento y yo también» ${ }^{52}$. El I2 de agosto Dauvergne se entrevistó con el intendente en casa de este para conocer qué medidas había adoptado. El intendente determinó que Wolters pudiera vender sus dos cañones, lo ingresado por uno para obtener liquidez y retomar el trabajo y lo obtenido por el otro para ser entregado a sus acreedores. Le hizo saber que mantuvo una fuerte disputa con el veedor, «que sabía que había sido el motor de todos los contratiempos que había tenido» el sueco. Le confirmó que si se producían nuevas quejas destituiría al veedor ${ }^{53}$. Dauvergne disuadió a Wolters de proseguir con este asunto, pues estimaba que la oferta del intendente era la mejor que podía obtener, a no ser que deseara reclamarle el pago por los daños ocasionados, lo que creía que era harto difícil que lo lograra ${ }^{54}$. En la Corte se habían efectuado gastos relacionados con este tema, y Dauvergne le indicó al sueco que si deseaba proseguir con el mismo debía enviar fondos a Madrid. No obstante, él le desaconsejó esa vía y le recomendó que cuando

49. Dauvergne a Maulévrier. 12/VII/1722. ADCN, 396PO/A/21.

50. Dauvergne [a Maulévrier]. 20/VII/1722. ADCN, 396PO/A/21.

51. Dauvergne [a Valcourt]. 28/VII/1722. ADCN, 396PO/A/21. El embajador remitió cartas a Wolters a través del cónsul.

52. Dauvergne [a Maulévrier]. 9/VIII/1722. ADCN, 396PO/A/21.

53. Dauvergne [a Maulévrier]. 16/VIII/1722. ADCN, 396PO/A/21.

54. Dauvergne a Valcourt. $6 / I X / 1722$. ADCN, 396PO/A/21. 
llegase el nuevo capitán general (Risbourq había sido relevado) acudiera a él, y el propio cónsul también le pondría en antecedentes 55 .

En cualquier caso, el asunto Wolters afectó de una manera muy profunda a las relaciones, ya de por sí pésimas, de Dauvergne con el intendente, pues desde entonces se inició un hostigamiento para que abonase los derechos de todos los artículos que adquiriera para el consumo, lo que él rechazaba de plano por atentar contra los privilegios consulares. Se convirtió en uno de sus más encarnizados adversarios (lo dibujaba como alguien en cuyo corazón solo anidaba el veneno y la malicia, que en su caso era más peligroso pues lo ocultaba bajo la excusa de la defensa de los intereses del rey). Una indiscreción se hallaba en el origen de la acentuación del enfrentamiento: «el intendente busca todas las ocasiones para perjudicarme, habiendo averiguado que yo había escrito sobre su conducta con ocasión del señor Wolters, y habiéndome dicho que se le había enviado copia de mis cartas» ${ }^{56}$.

Recuperada la libertad, en 1723 Wolters retomó su actividad en la ría de Vigo ${ }^{57}$. Incluso hay constancia de que recibió un barco con nuevas máquinas, buzos y obreros, que debían trabajar tanto en invierno como en verano. El cónsul afirmó que realizó todo lo que estaba en su mano para instarle a proseguir en su tarea ${ }^{58}$. No obstante, un año más tarde, Dauvergne solicitó al nuevo embajador protección para Wolters y que emplease sus buenos oficios para que se le hiciera justicia y se le resarciera de las vejaciones que había padecido ${ }^{59}$. Coulanges se comprometió a defenderle ${ }^{60}$ y Dauvergne le dio las gracias por su implicación, pues esto creyó que aseguraba que se renovase su acuerdo de extracción en la ría de Vigo con España ${ }^{61}$. Sin embargo, Wolters abandonó Galicia y en 1724 se encontraba en Huelva dedicado a la explotación de minas. Su experiencia submarina, como hemos visto, estuvo caracterizada por los problemas económicos (dificultades financieras que le obligaron a vender algunas de sus propiedades, acreedores que le hostigaban, socios que le reclamaron una parte de lo recuperado), las tensiones con sus empleados por impagos y culminó con su arresto. Todo contribuyó a que Wolters sustituyera las profundidades de la ría de Vigo por las de una mina onubense.

\section{ALEXANDRE GOUBERT (1728-1733)}

En I728 la extracción de los restos de las naves naufragadas en I702 se confió a una compañía francesa, a la que sucedió un pequeño comerciante de Vigo (Juan Antonio Rivero) por la inacción de la concesionaria gala ${ }^{62}$, para volver a tomar parte

55. Dauvergne a Valcourt. 13/IX/1722. ADCN, 396PO/A/21

56. Dauvergne [a Maulévrier]. 10/1/1723. ADCN, 396PO/A/22 bis.

57. Dauvergne [a Maulévrier]. 14/III/1723. ADCN, 396PO/A/20.

58. [Dauvergne a Maulévrier]. [¿IV?/1723]. ADCN, 396PO/A/20.

59. Dauvergne [al marqués de Coulanges, embajador en Madrid]. 9/I/1724. ADCN, 396PO/A/23.

6o. [Coulanges] a Dauvergne. San Ildefonso, 25/1/1724. ADCN, 396PO/A/23.

61. Dauvergne [a Coulanges]. 6/II/1724. ADCN, 396PO/A/23.

62. La concesión a Rivero se debió al hecho de que la Corona observó que Goubert no estaba llevando a cabo trabajo alguno en la ría. Véase PATıÑo GómEZ, 2014: 83. 
los franceses en I732. Alexandre Goubert era capitán de navío y subinspector de construcciones navales de la Marina francesa ${ }^{63}$. Era autor de diversos inventos que se proponía emplear en la ría de Vigo ${ }^{64}$. El cónsul se mostró muy solícito con la nueva compañía responsable de los trabajos, llegando a proporcionarle de su propio dinero una cantidad que se le pidió. La compañía encaminó a Vigo cuatro navíos, pero los trabajos se retrasaron, pues se estaba a la espera de recibir las órdenes desde la Corte. Para Dauvergne la capacidad de la empresa española no admitía comparación con la francesa, y esto explicaba su elección:

\begin{abstract}
He aquí la reflexión que yo hago y la que hay que hacer entre el señor Rivero y esta compañía. El señor Rivero, a quien se ha acordado el privilegio de retirar los navíos naufragados en Vigo en 1702, los efectos y restos, mediando el 30\%, en perjuicio del que había sido acordado a la compañía francesa en 1728 a razón del 6\%, no habrá dejado de extrañar por la diferencia que hay del tratado de uno al del otro. Pero tomado por el buen lado, se verá que la compañía dará más a su majestad católica en un mes que Rivero en diez años. Es fácil de probarlo. La compañía que ha obtenido este privilegio en 1728 comenzó desde ese momento a ponerse a trabajar con fruto para limpiar tan bien este puerto que no queda ni carcasa ni vestigio de todos los barcos que naufragaron allí. Construyeron cuatro barcos de una nueva invención de 150 toneladas cada uno [en el puerto de Tolón], les dotaron de todos los aparejos y aparatos convenientes para esta empresa, se hicieron cordajes específicos y todos los instrumentos a proporción para sacar los navíos y efectos enterrados en el fondo desde hacía treinta años, lo que, unido a su vigilancia, experiencia y cuidados, no dejó de costarles, ante de comenzar los trabajos, cerca de un millón.

Por lo que respecta al señor Rivero, pequeño comerciante establecido en esta ciudad que no ha conocido jamás qué es la navegación y aún menos el salvamento, no tiene capacidad de gastar 200 pistolas, y cuando encuentre unos tontos [dupes] para formar una compañía no llegará nunca a alcanzar un fondo de 10 a 12000 piastras para esta empresa, e incluso aunque encontrara sumas más considerables, no tiene ni la experiencia ni las máquinas y no podría encontrar aquí los oficiales, marineros y obreros de los que se necesita en semejantes casos ${ }^{65}$.
\end{abstract}

Rivero, de quien Dauvergne reitera que «su comercio es muy pequeño y sus asuntos muy trastornados» (es decir, carece de capacidad financiera para llevar a cabo una labor de esta magnitud), había obtenido una concesión en febrero de 1732 para trabajar durante tres años en el rescate de los restos de las naves de España y de Francia ${ }^{66}$. El cónsul no había informado previamente sobre él y su proyecto porque Rivero simplemente solicitó esta concesión con la idea de lograr un crédito y conseguir que alguien se le uniera, pero después de seis meses no había encontrado

63. Sobre su desempeño como marino véase Mémoires et correspondance du capitaine de vaisseau Renau d'Éliçagaray, du sous-inspecteur des constructions navales Goubert et du directeur des constructions navales Groignard, 1679-1794. AN, MAR/D/1/10.

64. Sobre sus inventos véase Service Historique de la Défense (Château de Vincennes, París), Ms. 248

65. Dauvergne [a Gérard Lévesque de Champeaux (encargado de los asuntos de marina y de comercio de Francia en España, Sevilla)]. 5/XI/1732. ADCN, 396PO/A/45.

66. Las fuentes francesas señalan tres años, pero hay quien indica que el contrato era por seis años. PATIÑo GómEZ, 2014: 83 
ningún «inocente». Además, sus buzos debían llegar de Inglaterra y no había aparecido ninguno. Por otro lado, el cónsul inglés informó a Dauvergne que para que los buzos fueran un hecho le habían exigido más garantías. Rivero incluso visitó a Dauvergne para mostrarle su concesión, a lo que este le respondió que él tenía órdenes de vigilar las operaciones de extracción ${ }^{67}$. En suma, no consideraba que esta empresa pudiera llegar a tomar forma. Sin embargo, Rivero construyó dos barcas y parecía decidido a seguir adelante, de modo que informó a París que podía haber problemas $^{68}$. Y, de hecho, Rivero comenzó las extracciones. Al principio solo contaba con un buzo inglés, pero llegó un pequeño barco de Inglaterra en el que el capitán y toda la tripulación eran buzos, con quienes estableció un acuerdo. Extrajeron cinco cañones de hierro y ochenta balas de diferentes calibres ${ }^{69}$.

Finalmente, el cónsul recibió las órdenes y despachos para el conde de Ittre, comandante general de Galicia, y Bernardino Freire, ministro principal de Marina del departamento de Ferrol, y se lo comunicó a Chambelain de Leonval (enviado por Goubert y que había llegado a La Coruña el i7 de julio), «lo que ha tranquilizado su espíritu y le ha puesto muy contento». El retraso de estas órdenes le habían provocado inquietud, creyendo que habían sido interceptadas por su tardanza. El cónsul se comprometió a ofrecer todos los servicios posibles a los integrantes de la compañía y a redoblar sus atenciones, siendo «duro contra todos sus opositores». Por el vicecónsul de Vigo (Juan Bautista $\mathrm{Magi}^{{ }^{\circ}}$ ) supo que habían llegado allí dos barcos de esta compañía, mientras que un tercero lo hizo a Portonovo, muy maltratado y habiendo perdido el timón y siendo abandonado por la tripulación, mientras que del cuarto no se tenían noticias ${ }^{71}$. Finalmente, las dos últimas embarcaciones arribaron a Vigo. El embajador, conde de Rottembourg, ordenó al encargado de comercio de la embajada que remitiera al vicecónsul en Vigo una carta en favor de la compañía. Una vez recibida el vicecónsul hizo saber que obedecería puntualmente, ofreciendo todos sus servicios a los integrantes de la compañía ${ }^{72}$. Leonval, acompañado por el canciller del consulado (Fromont), se desplazó a Betanzos para entregar al conde de Ittre las órdenes de la Corte de España relativas al privilegio de la compañía de Goubert y este expidió las suyas al ministro principal de Marina en Ferrol para asistirles en sus operaciones, quien nombró un subdelegado. Ittre facilitó a Leonval una carta para el gobernador de Vigo en la que le ordenaba que eliminara cualquier obstáculo que se le planteara a la compañía ${ }^{73}$. Este proceder tan cauteloso obedecía a un deseo de contar con la protección de la principal autoridad en Galicia y con todos los beneplácitos administrativos. El apoyo consular no se limitó en esta ocasión

67. Dauvergne a Jean-Frédéric Phélypeaux (conde de Maurepas, secretario de Marina). 11/VI/1732. ADCN, $330 \mathrm{PO} / 1 / 1$.

68. Dauvergne a Maurepas. 23/VII/1732. ADCN, 330PO/1/1.

69. Dauvergne a Maurepas. $1 / X / 1732$. ADCN, 330PO/1/1.

70. Véase Patiño Gómez, 2014: 80.

71. Dauvergne [a Champeaux]. 12/XI/1732. ADCN, 396PO/A/45

72. Juan Bautista Magi a Champeaux. Vigo, 16/XI/1732. ADCN, 396PO/A/45. El vicecónsul, de origen florentino, se hallaba en Vigo desde 171l, dedicado al armamento de naves corsarias. En el pasado había tenido relación con Wolters, pues en 1722 Avilés le cedió su parte en la empresa. PATIÑo GómEZ, 2014: 80.

73. Dauvergne a Maurepas. 19/XI/1732. ADCN, 330PO/1/1. 
al auxilio material y la protección jurisdiccional, sino que debió hacer frente a los trastornos que pudiera provocar el hecho de que el rey hubiera emitido un decreto en favor de un comerciante coruñés sin consideración al privilegio expedido en I728 a la compañía de Goubert, con exclusión de cualquier otra. En esta ocasión, como en la precedente, la isla de San Simón fue la base de operaciones de la empresa.

Los problemas se manifestaron de manera inmediata. Antes de que comenzaran siquiera los trabajos se intentó un proceso contra el vicecónsul de Francia en Vigo por haber acompañado a Leonval a reconocer los lugares en que tuvo lugar el naufragio de la flota hispano-francesa, lo que asustó sobremanera al vicecónsul, a pesar de todos los intentos de Dauvergne para tranquilizarle ${ }^{74}$. El temor era fundado, puesto que Dauvergne convino con Leonval no hacer nada hasta recibir órdenes del embajador en Madrid y actuar de manera concertada. No obstante, los contratiempos más serios fueron con Rodrigo de Ricla, administrador general de aduanas de Galicia, residente en Pontevedra. Este informó que todos los utensilios y máquinas que había traído la compañía debían pagar derechos, lo que provocó la estupefacción del cónsul: «como si en algún país se exigieran derechos de un obrero que llega a trabajar allí con sus herramientas». La oposición a esta decisión por parte del vicecónsul de Vigo tuvo como consecuencia que fue arrestado en su casa y multado con 500 ducados. Además, Ricla colocó cadenas en las puertas de los almacenes donde los efectos habían sido depositados tras ser desembarcados, de modo que la compañía no podía iniciar su tarea. Había hecho acto de aparición el adversario que centró todas las preocupaciones de Dauvergne desde entonces, del que anheló «que fuera borrado para que no se hablara más de él» ${ }^{75}$.

Dauvergne señaló que, de manera sorprendente, ningún miembro de la compañía se había puesto en contacto con él para informarle de sus avances desde que se encontraban en Vigo, lo que en el caso de Leonval le extrañaba más todavía por las atenciones con que le agasajó durante su estancia en La Coruña, previa a la llegada de los barcos a Vigo. Esta será la norma, pues las empresas solo acuden al cuerpo consular cuando surgen problemas, pero no desean ser controladas por este. No obstante, Dauvergne estaba al día de todo lo que acontecía porque el vicecónsul le informaba de manera puntual en todos sus correos. De este modo, supo que estaban trabajando en febrero de I733 en la extracción de dos barcos españoles. Deseaba que la empresa tuviera éxito, «aunque solo sea por el honor de la nación» ${ }^{6}$. La compañía aguardaba la llegada de Goubert padre (Alexandre, el hijo se llamaba Diègue), quien se dirigía a Vigo en un barco con destino en Lisboa, que fue obligado a realizar escala en Ferrol por el viento el in de febrero. Desde la ciudad departamental escribió al cónsul señalándole que no tenía dinero español y que precisaba 50 piastras y conocer el coste de un coche para dirigirse a Vigo. Dauvergne le envió el dinero y le rogó

74. Dauvergne a Maurepas. 8/X/1732. ADCN, 330PO/1/1.

75. Dauvergne [a Champeaux]. 9/XII/1732. ADCN, 396PO/A/45. No ahorra críticas sobre él: «ha sido expulsado del regimiento de Murcia, donde era oficial, aborrecido de su cuerpo. Ha llegado a este empleo por medio de la hermana de su mujer, que se dice que es bonita. Este hombre es un antropófago enemigo jurado de la nación, a la que veja y roba impunemente con preferencia a las demás, lo que no ahorra tampoco a la suya».

76. Dauvergne [a Champeaux]. 11/II/1733. ADCN, 396PO/A/46. 
que aceptara su casa en La Coruña para descansar mientras esperaba un coche. La meteorología impidió el viaje y durante cinco días nadie llegó a La Coruña procedente de Ferrol. Días más tarde, el I9, el vicecónsul de Ferrol le hizo saber que el barco de Goubert se había hecho a la mar la jornada anterior ${ }^{77}$. Finalmente, el vicecónsul informó de la llegada a Vigo de Alexandre Goubert. La compañía decidió comenzar sus trabajos con el navío español Tojo, que en la marea baja casi estaba descubierto completamente, y que aparentaba ofrecer menos dificultad. Sin embargo, el resultado no fue el previsto: «Cuando ha sido cuestión de sacarlo todo entero, la proa se ha partido y roto en diversos trozos y solo han podido sacar algunos restos que han transportado a tierra $\gg^{78}$. La labor se iniciaba de modo poco esperanzador.

El cónsul informaba a la embajada puntualmente de cuanto efectuaba la compañía de Goubert, remitiendo incluso las cartas originales que recibía de su vicecónsul en Vigo, que solicitaba que le devolvieran ${ }^{79}$. En la primavera de 1733 los trabajos se encontraban en el mismo punto que en su inicio, con la diferencia de que se habían efectuado cuantiosos gastos y estos se estaban incrementando, lo que determinaba que los socios de la compañía «no tengan muchas posibilidades» de recuperarse. Los resultados de las operaciones de extracción no eran los esperados ${ }^{80}$. A esto se sumaba un problema imprevisto, pues muchos de sus marineros desertaron para alistarse en la Marina española. Informaron de esto al cónsul y este se puso en contacto con Francisco Cornejo, comandante general del departamento de Ferrol («este general que creo justo y bien intencionado para la nación»), pidiéndole que le entregara aquellos que se encontraran en Ferrol y La Graña, garantizándole bajo su palabra de honor que no se les haría ningún daño. Este inmediatamente dio orden de que fueran localizados y enviados escoltados por soldados de Marina. Una vez fueron detenidos (se capturó a cinco franceses, tres de los cuales eran de los buscados), desde Vigo se envió al capitán de uno de los barcos que los condujo esposados de regreso por tierra ${ }^{81}$. La recuperación de los marineros no contribuyó a que se modificara el resultado de las actividades de extracción. Los avances se ralentizaban, mientras que los gastos se incrementaban notablemente por la destrucción de máquinas y cuerdas $^{82}$. A finales de la primavera la situación empezaba a ser insostenible pues los oficiales se marchaban, los marineros incrementaban las deserciones, que se producían todos los días (ahora encaminándose hacia el vecino Portugal), sin que se pudieran remediar. Se llegó a temer no por la viabilidad de la compañía, de la que no se dudaba, sino que de seguir esta sangría no tendrían ni tan siquiera tripulación para regresar con los barcos a Tolón ${ }^{83}$. No obstante, Goubert comprometió a Jean Lefranc de Lompré (director de la compañía) para realizar en junio de I733 una gran operación el día I5, prometiéndole que esta tendría éxito, pero que culminó en fracaso. No en

77. Dauvergne [a Champeaux]. 25/II/1733. ADCN, 396PO/A/46.

78. Dauvergne [a Champeaux]. 11/III/1733. ADCN, 396PO/A/46.

79. Véase Dauvergne [a Champeaux]. I/IV/1733. ADCN, 396PO/A/46.

80. Dauvergne a Maurepas. 29/IV/1733. ADCN, 330PO/1/1.

81. Dauvergne a Maurepas. 6/V/1733. ADCN, 330PO/1/1. Véase también Dauvergne [a Champeaux]. $13 / \mathrm{V} / 1733$. ADCN, 396PO/A/46

82. Dauvergne a Maurepas. 13/V/1733. ADCN, 330PO/1/1.

83. Dauvergne a Maurepas. 3/VI/1733. ADCN, 330PO/1/1. 
vano, el vicecónsul afirmaba que Goubert encontraba siempre razones plausibles para justificar su falta de resultados ${ }^{84}$. Sin embargo, Dauvergne ya era muy pesimista: «incluso creo que han puesto todo en práctica para el éxito de su empresa y que hoy no les queda otra posibilidad que regresar a su departamento» ${ }^{85}$. El final se aceleró por las diferencias que surgieron entre los directores de la compañía, que actuaron como catalizadores de la descomposición, culminando a mediados de julio con la vuelta a Francia de embarcaciones y hombres:

la semana pasada los señores Goubert y Lefranc tuvieron entre ellos grandes altercados. Este último fue acusado de impostor y de bribón y el señor Lefranc hizo cesar inmediatamente el trabajo de la operación, en base a órdenes que había recibido de la compañía. Así pues, los señores Goubert, padre e hijo, se retiraron a Vigo para embarcarse en una nave bretona y retornar a Francia, y los otros interesados y oficiales se dispusieron también a regresar, haciendo armar sus cuatro barcos con toda diligencia, esperando solo un pequeño barco de Burdeos que les debe suministrar los víveres necesarios para su travesía ${ }^{86}$.

A los escollos que planteó la extracción de restos de las naves del fondo de la ría de Vigo, se añadieron en la superficie los suscitados por los administradores de rentas. El I3 de julio de I733, Juan Luis Jiménez de Saboya (subdelegado de la intendencia), mandó que la compañía abonase los derechos de lo que hubiera introducido en España, exceptuando las máquinas, artificios y aparejos relativos al buceo, tal y como había señalado José Patiño en una carta orden de I6 de enero, pues no tenían privilegio especial para estar exentos. El pago se exigía sobre el vino que habían desembarcado y consumido. El 28 de julio se reiteró a Lefranc y a Fábregas (vicecónsul en Vigo) que debían ajustarse con Gaspar Caballero, administrador de rentas en Redondela (donde se incluía Rande y la isla de San Simón), el pago de los derechos sobre el vino consumido en la isla de San Simón. Los franceses mostraron su desacuerdo:

dijeron que el vino que han desembarcado en dicha isla fue solo por vía de depósito, por estar los navíos ocupados con las máquinas del buceo, y del mismo que se desembarcó fue para bordo de dichos navíos la mayor porción en donde se consumió, y por lo que mira a lo que se consumió en tierra están prestos a pagar los derechos que causaron sin omisión alguna, y de querer obligarles el presente escribano al pago de lo que se consumió a bordo, por no haber tal práctica, protestan este exceso y más recursos que les competan... Y que de todo el vino que se depositó quedaron nueve barricas para los oficiales y criados, y se hallan seis consumidas y las tres en serlo, y por lo que mira a los derechos de las seis están prontos a pagarlos, y lo mismo harán de las otras en consumiéndolas ${ }^{87}$.

\footnotetext{
84. Dauvergne [a Champeaux]. 10/VI/1733. ADCN, 396PO/A/46.

85. Dauvergne a Maurepas. 24/VI/1733. ADCN, 330PO/1/1.

86. Dauvergne a Maurepas. 22/VII/1733. Hacemos notar que no deseaban adquirir nada en España para evitar tener que pagar derechos. Los Goubert partieron de Vigo el 19 de julio, mientras el resto se afanaba en embarcar todas las máquinas para poner rumbo a Tolón. Dauvergne a Maurepas. 29/VII/1733. Los cuatro barcos de la compañía salieron de Vigo el 29 de agosto, mientras que Lefranc regresó por tierra. Dauvergne a Maurepas. 9/IX/1733. ADCN, 330PO/1/1.

87. Juan Antonio de Verea y Aguilar (en nombre de Santiago González del Solar, recaudador de rentas provinciales en Galicia). Redondela, 6/VIII/1733. ADCN, 396PO/A/50.
} 
Si bien inicialmente se negaron, indicando que el vino era para la gente de la compañía y que se consumió a bordo, fueron matizando, como vemos, y transigiendo. Los franceses estaban dispuestos a pagar por el vino consumido en tierra (en la isla de San Simón), pero no por el que lo había sido a bordo de sus naves. Lo que en primera instancia pareció una mínima discrepancia ${ }^{88}$ terminó en un grave enfrentamiento. Lefranc, aunque ante el escribano pareció claudicar, se reafirmó pocos días después en que el vino se hizo venir de Francia y se consumió a bordo de sus naves por los trabajadores de la compañía. Añadió que se estaba ante una violación del derecho de las naciones (en su opinión, el derecho de consumo solo afectaba al realizado en tierra) y que esta exacción no podía ser tolerada. Se planteó dejar España hacia el 20 de agosto y que Fábregas quedase como responsable de algunos pequeños asuntos pendientes ${ }^{89}$. Desde la embajada se ofreció asesoramiento jurídico, pues se consideraba que este asunto no tenía ningún recorrido:

Las mercancías que se desembarcan por la razón que sea con el designio de reembarcarlas y sin ten deseos de verlas no deben pagar ningún derecho, solo propiamente lo que entra en el país y que se consume allí debe derechos, todos los tratados están formulados así. Solo sería necesario que el señor Patiño os contemple el vino que usted ha llevado a tierra como un depósito, del mismo modo que nuestras máquinas y aparatos estaba acordado que usted no lo pagase. El vicecónsul de Vigo no debería haber dejado de informaros que lo que usted lleva a tierra con estas circunstancias con el objetivo de rearto, no debiendo ningún derecho, había que hacer una declaración a los oficiales reales de su majestad católica en la cual explicaseis con qué objeto usted desembarcaba este vino y que vuestra intención era volver a llevarlo a bordo9 .

El vicecónsul, consciente de que precisaba un testimonio ajeno a la compañía sobre cuál había sido el proceder cuando se habían recibido víveres del extranjero intentó obtenerlo del escribano de rentas reales, quien se excusó a no ser que se lo ordenase el comandante de la plaza de Vigo. Así pues, Fábregas le dirigió un oficio a este último, donde le presentaba un resumen de lo acontecido, haciendo hincapié en que si las barricas estuvieron en tierra fue para desembarazar los barcos y no entorpecer las faenas a bordo, y añadiendo que si se consumió algún vino por los marineros en la isla era «lo mismo que si lo hicieran a bordo», pues en San Simón también trabajaban, ya que allí se encontraban muchos instrumentos y aparejos para la fábrica de lo necesario para el buceo ${ }^{91}$. Al hallarse ausente el comandante, fue el sargento mayor de Vigo (Antonio Fernández Cevallos) quien instó al escribano de rentas reales a redactar el documento. Este informó que el 3 de marzo de

88. El embajador (conde de Rottembourg) estimó este asunto de tan pequeña entidad que afirmó que no merecía presentar un oficio. Documento dirigido a Champeaux. [Sin fecha, (1733)]. ADCN, 396PO/A/50.

89. Lefranc [¿a Champeaux?]. Vigo, 9/VIII/1733. ADCN, 396PO/A/50.

90. [¿Champeaux?] a Lefranc. Segovia, 26/VIII/1733. ADCN, 396PO/A/50. Tachado en el original.

91. Fábregas al comandante de la plaza de Vigo. Vigo, [IX/1733]. ADCN, 396PO/A/50. Por otra parte, aunque se aludía solo al vino y la harina, la compañía trajo de Francia todo género de víveres para la asistencia y manutención de sus hombres. Obviamente, la diferencia radicaba en que los primeros llegaron en sus cuatro barcos al principio, mientras que ahora se trataba de una embarcación enviada desde Francia ex profeso. 
I733 llegó a Vigo un navío inglés procedente de Burdeos que declaró en la aduana que traía 40 barricas de vino de Burdeos y Ioz barriles de harina para la compañía. La descarga se efectuó en la isla de San Simón los días I8, 20 y 2i de marzo, con asistencia de Rodrigo de Niela y Correa, administrador general de la real renta de aduanas en Galicia: 6 barricas de vino para los directores del buceo, 32 barricas de vino ordinario para las tripulaciones, y con las 2 restantes se rellenaron las anteriores. Los I02 barriles de harina también se llevaron a tierra. Tanto el vino como la harina tuvieron como consumidores exclusivos a las tripulaciones:

He visto en el último día de dicha descarga remitir a bordo de cada uno de los cuatro navíos de la compañía que se hallaban para dicho buceo seis barricas de dicho vino. Y después de ello, en una de las ocasiones que he ido en compañía de dicho señor administrador general a la expresada isla, también he visto conducir cuatro barricas de dicho vino a bordo de dichos cuatro navíos. Y lo mismo he visto ejecutar de otras cuatro para bordo de los dichos navíos en otra distinta ocasión que fui con dicho señor administrador a la expresada isla. Y en cuanto a la harina me consta que esta la fabricaban en pan, que cocían en dicha isla y remitían desde ella a dichos navíos ${ }^{92}$.

Lefranc abandonó Vigo por tierra el 28 de agosto, el mismo día que partieron los barcos. La compañía ponía punto final a los trabajos y abandonaba Galicia, pero las reclamaciones de los derechos adeudados persistieron, si bien ahora fue el vicecónsul quien hizo frente a este tema. Fábregas envió a Lefranc una copia de las diligencias contra él para que informara a Champeaux, pero al no mencionar nada aquel en su correspondencia creyó que podía haberse olvidado, «estando muy ocupado». El vicecónsul accedió a pagar los derechos de entrada de las barricas de vino en la aduana y el ı\%, pero se negó a abonar los derechos de alcabala, que eran de un real por arroba, arguyendo lo ya indicado de que se consumió a bordo y no en tierra. También se le requirió la alcabala por el vino que compró en Vigo destinado al consumo de la compañía durante el tiempo que estuvieron allí, y que enviaba a sus embarcaciones conforme se le solicitaba para los marineros. Esto se percibió como una novedad peligrosa en la que no se podía ceder:

Hasta ahora no hay ningún ejemplo de que se haya pagado el dicho derecho de tales vinos que no son vendidos en el país. Y si el administrador de la alcabala gana su punto en esto, hará de ahora en adelante pagar estos derechos a todos los barcos franceses que entren aquí por el vino que ellos necesiten ${ }^{93}$.

Los franceses estimaron esta actuación como arbitraria, máxime cuando a un segundo barco que llegó con víveres para la compañía no se le exigió ninguno de estos derechos por orden de Patiño. En cualquier caso, la actitud reacia al pago

92. Memoria de Juan Antonio Blanco, escribano de rentas reales, a instancia de Antonio Fernández Cevallos. Vigo, 13/IX/1733. ADCN, 396PO/A/50.

93. Fábregas a Champeaux. Vigo, 13/IX/1733. ADCN, 396PO/A/50. 
de derechos la compañía no los circunscribía a los que les exigían las autoridades españolas, pues cuando de manera apresurada dejó Galicia también se negó a abonar los derechos consulares por los cuatro barcos. Lefranc dejó como prueba de su buena voluntad la promesa de que si el secretario de Marina de Francia lo ordenaba haría frente al importe, pero nada más se supo ${ }^{94}$. La circunstancia de que la inversión realizada no obtuviera el rédito esperado, pues las extracciones no estuvieron jamás a la altura de las expectativas, y que sin embargo los gastos superaran las previsiones, sumado a los problemas de gestión (fugas de trabajadores) y a la perseverante actuación de los recaudadores de rentas, configuran un cúmulo de causas que terminaron por introducir disensiones en la dirección de la compañía y motivaron la decisión de abandonar Vigo de manera casi abrupta. El cuerpo consular que le había auxiliado en todo momento también fue quien saldó sus deudas.

\section{CONCLUSIÓN}

Las empresas de rescate de los pecios, de sus restos, se centraron en la recuperación de los elementos que añadían a su tasación una utilidad, lo que explica que la atención se centrase principalmente en los cañones y anclas. La documentación consular no hace referencia jamás a la extracción de monedas u otros objetos valiosos, pero evidentemente estos se hallaron entre lo recuperado, tanto por el interés que las compañías tenían en los mismos por su enorme valor como por la facilidad de su rescate $^{95}$. El fracaso de las iniciativas que obtuvieron concesiones para trabajar en la ría de Vigo obedeció, en primer lugar, a la dificultad de los trabajos submarinos. La batalla de Rande en I702 y el hundimiento de la flota hispano-francesa (las fuentes francesas hablan de «naufragio», como si la causa fuera de naturaleza meteorológica y no bélica) no jugó el papel que hubiera sido de suponer para incrementar el interés en el seno de la Marina española por el buceo, debido a que las compañías que llegaron a Vigo contrataron a sus especialistas en trabajos submarinos en el norte de Europa. Ahora bien, sí que se emplearon aquí en los primeros años de las décadas tercera y cuarta del siglo XVIII los artilugios más innovadores, prototipos, modelos que se ensayaron casi por primera vez y que precisaron de muchas mejoras y transformaciones para poder ser empleados con seguridad y utilidad práctica. Así pues, las compañías de Wolters y Goubert fueron las responsables de la introducción en España de una tecnología novedosa y de especialistas en el buceo franceses, finlandeses e ingleses. La actividad económicamente no fue rentable para niguna de ellas, a lo que se sumó la actitud de los responsables de la recaudación de las rentas en Galicia, que no fue muy conciliadora, y la circunstancia de que la Corona no respetó la exclusividad de las concesiones ${ }^{96}$.

94. Dauvergne a Maurepas. 21/X/1733. ADCN, 330PO/1/1.

95. A Wolters España le obligó a renunciar a todas las piezas de oro y de plata que localizara en los pecios. BLOT, 2002: 229.

96. Las compañías tampoco cumplieron con sus compromisos. Por ejemplo, Wolters vendió parte de los efectos rescatados en Inglaterra. Véase PATIÑo GómEZ, 2014: 79. 
El fracaso, pues tanto las labores de Wolters como las de Goubert se saldaron con enormes gastos y en ocasiones con más tiempo dedicado a hacer frente a las trabas administrativas que buceando en la ría de Vigo, no fue óbice para que se sucedieran los asientos para llevar a cabo trabajos de extracción en Rande. La misma compañía que de manera repentina dejó Galicia en I733, «sin haber logrado el intento» y tras realizar «gastos crecidos», retornó en $\mathrm{I} 738^{97}$, con importantes socios y el respaldo explícito del secretario de Marina de Francia ${ }^{98}$. En esta ocasión el problema inicial surgió en París, pues otra persona (Pierre Boyer) el i4 de abril manifestó que el privilegio de Goubert estaba suprimido y que ella estaba en posesión de una licencia exclusiva por dos años ${ }^{99}$. Una vez en Vigo, ahora Goubert sí logró levantar el Tojo y vararlo en la costa, pero a un coste exorbitado: dos millones de francos ${ }^{\mathrm{IOO}}$. Aunque no les acompañó el éxito, estas compañías fueron las pioneras y consideramos imprescindible para comprender su devenir en Galicia conocer las dificultades que tuvieron que afrontar en tierra, para las que no les sería de utilidad la tecnología, pero sí el apoyo del naciente cuerpo consular. Desde entonces hasta la actualidad, casi sin solución de continuidad, se suceden los intentos por recuperar los restos de las naves hundidas en 1702 en la ría de Vigo ${ }^{\text {Ior }}$.

97. En esta etapa destacó la elaboración de un mapa con la ubicación de 22 pecios en el fondo de la ría realizado por el arquitecto de Marsella Pierre Veran Devaux, Plan de Vigo fait par P. V. Devaux Arch. Archivo General de Simancas, Mapas, Planos y Dibujos, 16, 199.

98. Maurepas a Louis-Marie de Lastre de Hègues (cónsul de La Coruña de 3 de marzo de 1736 a 1750). París, 29/ III/1738. ADCN, 396PO/A/6o. Previamente a la salida de los barcos que la compañía estaba aprestando en Nantes, el capitán de la marina mercante Charles Le Gris de Rosvelec llegó a La Coruña por tierra el 10 de abril y se desplazó a Vigo para comprar y talar la madera de pino necesaria para llevar a efecto esta empresa. El cuerpo consular recibió órdenes de prestarle toda su protección y de aplicarse al máximo para solventar cualquier traba que se le plantease. Se solicitó a la Corona de Francia una fragata para transportar todos los utensilios, máquinas, víveres y hombres.

99. A Le Gris (ya en La Coruña). París, s.f. [¿IV/1738?]. ADCN, 396PO/A/6o. Esto motivó que Le Gris solicitara a Champeaux que lograra del Conseil de Marine el reconocimiento de los documentos en favor de Goubert.

100. GOUBERT, 1755: 501-515.

101. Patiño GómEZ, 2014: 65-136. 


\section{BIBLIOGRAFÍA}

Abilleira Crespo, Yago, Los galeones de Vigo, Vigo, José Ramón Patiño Gómez, 2005.

Abilleira Crespo, Yago, «La batalla de Rande (ría de Vigo, I702). Última derrota de una Flota de Indias», Revista de Historia Naval, I29 (2015): 69-78.

Bartolomé Benito, Fernando, La plata ensangrentada. El virrey Sarmiento de Valladares y los galeones de Rande, Madrid, Almena Ediciones, 2013.

Blot, Jean-Yves, «As profundidades de Vigo», en Rande I702. Arde o mar, Vigo, Museo do Mar de Galicia, 2002: 22I-247.

Calvo Poyato, José, «Un episodio de la Guerra de Sucesión: El ataque anglo-holandés a la flota de Indias en la ría de Vigo», Revista de Historia Militar, 72 (I992): I65-I77.

Constela Doce, Xurxo, «Meirande', centro de interpretación da batalla e o patrimonio cultural de Rande, unha experiencia de musealización», Gallaecia. Revista de arqueoloxía e antigüidade, 33 (2014): 325-358.

Fontenelle, Bernard de, «Eloge de M. Renau», en Histoire de l'Academie Royale des Sciences. Année M. DCCXIX. Avec les Memoires de Mathematique \& de Physique, pour la même Année. Tirés des Registres de cette Academie, Paris, Imprimerie Royale, I72I: IOI-I20.

García Hurtado, Manuel-Reyes, «The Greatest Treasure of the Spanish Armada in the Eighteenth Century. From the Battle of Rande (I702) to the Diving Schools (I787)», en Sünne Juterczenka (ed.), The Sea: Maritime Worlds in the Early Modern Period, Köln, Böhlau, 202I a: 439-453.

García Hurtado, Manuel-Reyes, «'Se puede vivir sin respirar'. Contexto teórico y marco práctico de los buzos en la Real Armada española en el siglo XVIIl», Páginas. Revista de Historia, vol. 13, 32 (202I b). En línea: https://revistapaginas.unr.edu.ar/index.php/RevPaginas/ article/view/50I/620 [consultado el 2 de mayo de 202I].

García Hurtado, Manuel-Reyes, «Un comisionado francés en la primera década del siglo XVIII en Galicia: Preparándose para una guerra», Vínculos de Historia (en prensa).

GARcía TAPIA, Nicolás, «En busca de tesoros bajo el mar: Invenciones de equipos para bucear en América», Revista de Indias, 203 (I995): 7-3I.

Goubert, Alexandre, «Relation des travaux faits pour relever le navire le Tojo, galion d'Espagne, coulé bas le io Octobre I702 dans la rade de Redondelle, baie de Vigo; relevé le 27 Septembre I74I, \& mis à terre le 6 Février I742», en Mémoires de mathématique et de physique présentés à l'Académie Royale des Sciences, par divers Savants, \& lûs dans ses Assemblées. Tome Second, Paris, Imprimerie Royale, I755: 50I-5I5.

IBERTI, Carlo, Tre miliardi nella Baia di Vigo, Milano, Ulrico Hoepoli, I942.

JAMBU, Jérôme, Tant d'or que d'argent. La monnaie en Basse-Normandie à l'époque moderne (XVI ${ }^{e}$-XVIII ${ }^{e}$ siècle), Rennes, Presses Universitaires de Rennes, 2013.

Juega Puig, Juan, La flota de Nueva España en Vigo. I702, Sada (La Coruña), Ediciós do Castro, 200I.

Kamen, Henry, «The Destruction of the Spanish Silver Fleet at Vigo in I702», Bulletin of the Institute of Historical Research, I00 (noviembre I966): I65-I73.

LEE, Owen, En busca del tesoro de la ría de Vigo [DVD], Vigo, Museo do Mar de Galicia, 2002.

Patiño Gómez, Ramón, Los tesoros de Rande. Relato de las expediciones realizadas para el rescate de las riquezas de la flota hispano-francesa derrotada en la batalla de Rande, Vigo, Yago Abilleira Crespo, 20I4. 
PatiÑo Gómez, Ramón, «Cuatro operaciones de guerra naval en la ría de Vigo en el siglo XVII», Glaucopis. Boletín del Instituto de Estudios Vigueses, 20 (2015): 53-66.

Patiño Gómez, Ramón, «Ataques fallidos en la ría de Vigo: siglos XVI-XVII», Glaucopis. Boletín del Instituto de Estudios Vigueses, 2I (2016): 287-316.

PatiÑo Gómez, Ramón, «Fortificaciones para la defensa de la ría de Vigo en los siglos XVI y XVII», Glaucopis. Boletín del Instituto de Estudios Vigueses, 23 (2018): I7I-2I2.

PotTer, John S., Jr., The treasure divers of Vigo Bay, New York, Doubleday \& Co., 1958. Traducido como En busca del tesoro de la ría de Vigo, Vigo, Museo do Mar de Galicia, 2002.

Rodríguez Cuevas, Tomás - Ivars Perelló, Juan, Historia del buceo. Su desarrollo en España, Murcia, Mediterráneo, 1987.

Rodríguez Elías, Avelino, La Escuadra de Plata. Estudio crítico y documentado sobre los famosos tesoros de los galeones de Vigo. Ilustrada con fotografías del conde Giorgio de Khevenhüller y Jaime G. Pacheco, Vigo, El Faro de Vigo, I935 (1994).

StÉnUit, Robert, Les épaves de l'or. Deux ans de plongées sur les galions de Vigo, Paris, AmiotDumont, 1958. Traducido al español como Tesoros y galeones hundidos. En busca del tesoro de la Ría de Vigo, Barcelona, Juventud, I969 y 1992 y al gallego como Os galeóns de Rande, Vigo, Edicións Xerais, I989 (en la portada se lee: «El tesoro de Indias que desde I702 duerme en los fondos de la ría de Vigo»).

VV.AA., Rande I702. Arde o mar, Vigo, Museo do Mar de Galicia, 2002.

Vázquez Gil, Bernardo Miguel, Los tesoros de la Ría de Vigo. Aproximación a la historia de los galeones de Rande, Vigo, Zenit, 1985. 



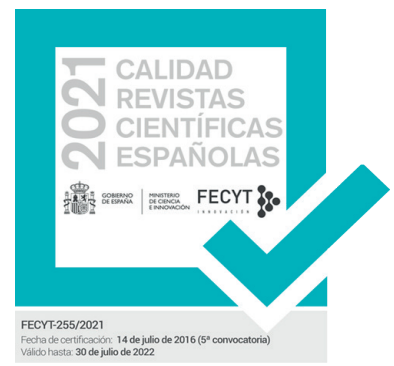

SERIE IV HISTORIA MODERNA

REVISTA DE LA FACULTAD DE GEOGRAFÍA E HISTORIA

AÑO 2021

ISSN: 1131-768X

E-ISSN 2340-1400

\section{4 \\ 西 ESPACIO, TIEMPO Y FORMA}

Monográfico - Special Issue: La política ultramarina de las monarquías ibéricas (circa 1700-1750): una historia de fracasos y éxitos relativos The Overseas Policy of the Iberian Monarchies (Circa 1700-1750): A History of Failures and Relative Successes

15 Roberto Quirós Rosado y MARIA FERnANDA BICALHO La política ultramarina de las monarquías ibéricas (circa 1700-1750): una historia de fracasos y éxitos relativos / The Overseas Policy of the Iberian Monarchies (Circa 1700-1750): A History of Failures and Relative Successes

\section{Guillaume Hanotin}

Defender negocios en tiempo de convulsión política: las elites mercantiles francesas durante la guerra de Sucesión española / Protecting Business in Time of Crisis: French Trademen during the War of Spanish Succession

\subsection{Maria Fernanda Bicalmo}

Ultramarino y el auge de los secretarios de Estado en Portugal durante la primera mitad del siglo XVIII / Sobre este modo de resolver e despachar os negócios. The decline of the Overseas Council and the Rise of the Secretaries of State in Portugal during the First Half of the $18^{\text {th }}$ Century

\section{9}

\section{VALENTINA FAVARò}

El fracaso de los proyectos de reforma en el virreinato peruano de principios

del siglo XVIII. Las propuestas de Carmine Nicola Caracciolo, príncipe de Santobuono the Eighteenth Century. The Proposals of Carmine Nicola Caracciolo, Prince of Santobuono

\section{7}

\section{ROBERTO QUIRÓS ROSADO}

Ecos de un mercantilismo truncado. El conde de Pinos Puente y la diplomacia comercial de Carlos VI en la corte de Lisboa (1723-1724) / Echoes of a Failed Mercantilism. The Count of Pinos Puente and the Commercial Diplomacy of Charles VI at the Court Of Lisbon (1723-1724)

\section{Junia Ferreira Furtado}

Portuguese America under Foreign Threat and the Creation of the Concept of uti possidetis in the First Half of the $18^{\text {th }}$ Century / La américa portuguesa bajo la amenaza exterior y la creación del concepto de uti possidetis en la primera mitad del siglo XVIII

\section{Miscelánea $\cdot$ Miscellany}

\section{José Antonio Mateos Royo}

con Cataluña / Trade Policy and Monetary Circulation in Aragon: Conflicts and Agreements with Catalonia (1535-1565)

\section{Fernando Altoé}

panegíricos atribuidos a la impresion. Un estudio de la trayectoria de dos the Trajectory of Two Panegyrics Attributed to João de Barros

\section{Francisco Velasco Hernández}

reino de Murcia (siglos XVI y XVII) / The Influence of the Berber Corsican on the Late Repopulation on the Coastal Area on the Kingdom of Murcia (XVI and XVII Centuries)

\section{José Antonio Martínez Martínez}

Criados, jornaleros y esclavos al servicio de la familia: la servidumbre de Serfdom of the Muñoz de Otálora in the $17^{\text {th }}$ Century

\section{Víctor Daniel Regalado González-Serna}

Benito de Medina a raíz de su ingreso en el cabildo catedral de Sevilla en 1669 / «Not a Single Good Portuguese». Accusations against Priest Alonso Benito de Medina when Entering the Cathedral Chapter of Seville in 1669

\section{José Herrera Reviriego}

organigrama comercial y militar de la Gober a tólo mitad del siglo XVII / "Only Time will Tell us»: The Role of Taiwan within the Commercial and Military Organization of the Philippine's Governoration during the First Half of the Seventeenth Century

\section{Manuel-Reyes García Hurtado}

de Rande, 1719-1733 / Vicissitudes of the Rescue Companies of the Sunken Ships in the Battle of Rande, 1719-1733

\subsection{Marcos de Miguel Muñoz}

Caballeros in 1769 


\section{4 ESPACIO, TIEMPO Y FORMA}

\section{Javier Tinoco Domínguez}

Tensiones sociopolíticas en el marco del catastro de Ensenada en Jerez de la Frontera: estudio de un conflicto institucional / Socio-Political Tensions within the Framework of Cadastre of Ensenada In Jerez de la Frontera: A Studying of an Institucional Conflict

\section{Pablo Fernández Albaladejo}

Fábulas de origen y gramática de nación en la España del siglo XVIII. A propósito de algunos trabajos de Francisco Martínez Marina / Origin's Fables and Grammar of Nation in the XVIII Century Spain. About some Works by Francisco Martínez Marina

\subsection{José María IÑURRITEgui Rodríguez}

Constitución increada: Francisco Martínez Marina y la crítica bíblica / Uncreated Constitution. Francisco Martínez Marina and Biblical Criticism

\subsection{David A. Abián Cubillo}

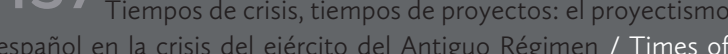
crisis, Times of Projects: The Spanish proyectismo during the Army's Crisis in the Ancient Regime

Taller de historiografía · Historiography Workshop

\section{Ensayos · Essays}

\subsection{ChrISTOPH ROSENMÜLLER}

«Tan peligrosas y feas conspiraciones»: la relación escrita por el embajador austriaco Christoph Migazzi en 1754 sobre la caída del marqués de la Ensenada / «Dangerous and Ugly Conspiracies». The Report of the Austrian Ambassador Christoph Migazzi on the Fall of the Marquis of la Ensenada in 1754

\subsection{Serge Gruzinskı}

Quelle histoire enseigner en 2021 ? / ¿Qué historia enseñar en 2021?

\subsection{Carlos Amate Pizarro}

Las relaciones hispano-chinas en el siglo XVI: síntesis e interpretación a la luz de la reciente historiografía / The Hispanic-chinese Relationship in the XVI Century: Synthesis and Interpretation in the Light of Recent Historiography

\section{Reseñas • Book Review}

521 Bolufer Peruga, Mónica, Arte y artificio de la vida en común. Los modelos de comportamiento y sus tensiones en el Siglo de las Luces, (Julio ArRoyo Vozmediano) 


\section{4 ESPACIO, TIEMPO Y FORMA}

525 Melón, Amando, Alejandro de Humboldt. Vida y obra (Carlos Martínez Shaw)

52 Commentary to Tatiana Seijas' review of The Atlantic World and the Manila Galleons: Circulation, Market, and Consumption of Asian Goods in the Spanish Empire (JosÉ LuIs GASCH TOMAS)

533 Braguier, Laurey, Servantes de dieu. Les beatas de la Couronne de Castille (1450-1600) (Manuela Águeda GARCÍA-GARRIDO)

539 Romeo, María CRuz; SAlomón, María Pilar; TABANERA, Nuria (eds.): Católicos, Reaccionarios y Nacionalistas. Política e identidad nacional en Europa y América Latina Contemporáneas (JAVIER M. Dos SANTOS)

54 Heredia López, Alfonso Jesús, El control de la corrupción en la Monarquía Hispánica. La Casa de la Contratación (1642-1660) (José Manuel Díaz Blanco)

17 Andújar Castillo, Francisco, El Atila de Madrid. La forja de un banquero en la crisis de la monarquía (1685-1715) (Aitor Díaz PAREdes)

551 Serrano Aviles, Javier y Mojarro, Jorge (eds.) Prada GonzALEZ, María (coord. de ilustraciones), En el archipiélago de la Especiería. España y Molucas en los siglos XVI y XVII (İ̃̃ıGo VALPUESTA VILLA)

555 Díaz Ceballos, Jorge, Poder compartido. Repúblicas urbanas, Monarquía y conversación en Castilla del Oro, 1508-1573 (JUAN SEbAstián Gómez GonZÁleZ)

51 Edelmayer, Friedrich, Massimiliano II, Filippo II I'Italia imperiale. II marchesato di Finale, i diritti imperiali e il «camino spagnolo» (RAFAEL VALLADARES)

56 Escribano-PÁEZ, José M., Juan Rena and the Frontiers of Spanish Empire, 1500-1540 (DAvid Martín Marcos)

56 ARnOLD, David, La Era de los Descubrimientos (1400-1600), Madrid, Alianza Editorial, 2021, 184 Pp., ISBN: 978-841362-172-2 (CARlos Amate Pizarro) 